\title{
The temporal course of COVID-19 anosmia and relation to other clinical symptoms
}

\author{
Aytug Altundag ${ }^{1}$. Ozlem Saatci ${ }^{2} \cdot$ Deniz Esin Tekcan Sanli ${ }^{3} \cdot$ Ozge Arici Duz ${ }^{4} \cdot$ Ahmet Necati Sanli $^{5} @$. \\ Oktay Olmuscelik ${ }^{6} \cdot$ Dastan Temirbekov $^{7} \cdot$ Sedat Giray Kandemirli ${ }^{8} \cdot$ Aysegul Batioglu Karaaltin $^{9}$
}

Received: 21 October 2020 / Accepted: 10 November 2020 / Published online: 25 November 2020

○) Springer-Verlag GmbH Germany, part of Springer Nature 2020

\begin{abstract}
Objective This study aimed to define the clinical course of anosmia in relation to other clinical symptoms.

Methods 135 patients with COVID-19 were reached by phone and subsequently included in the study. Olfactory functions were evaluated using a questionnaire for assessment of self-reported olfactory function. Patients were divided into four subgroups according to the presence of olfactory symptoms and temporal relationship with the other symptoms: group1 had only olfactory complaints (isolated, sudden-onset loss of smell); group2 had sudden-onset loss of smell, followed by COVID-19 related complaints; group3 initially had COVID-19 related complaints, then gradually developed olfactory complaints; and group4 had no olfactory complaints.

Results In total, 59.3\% of the patients interviewed had olfactory complaints during the disease course. The olfactory dysfunction severity during COVID-19 infection was significantly higher in group1 compared to groups 2 and 3 . In groups 1-3, the odor scores after recovery from COVID-19 disease were significantly lower compared to the status prior to disease onset. The residual olfactory dysfunction was similar between groups 1 and 2, but was more evident than group3. Mean duration for loss of smell was $7.8 \pm 3.1(2-15)$ days. Duration of loss of smell was longer in groups 1 and 2 than in group3. Odor scores completely returned back to the pre-disease values in 41 (51.2\%) patients with olfactory dysfunction. Rate of complete olfactory dysfunction recovery was higher in group 3 compared to groups 1 and 2.

Conclusion In isolated anosmia cases, anosmia is more severe, and complete recovery rates are lower compared to the patients who have other clinical symptoms.
\end{abstract}

Level of evidence Level 4.

Keywords COVID-19 $\cdot$ Anosmia $\cdot$ Sudden $\cdot$ Recoverable $\cdot$ Olfactory dysfunction

\section{Introduction}

Coronavirus disease 2019 (COVID-19), caused by severe acute respiratory syndrome coronavirus 2 (SARS-CoV-2), has resulted in a worldwide pandemic [1]. Through the

Ahmet Necati Sanli

ahmetnecatisanli@gmail.com

1 Department of Otorhinolaryngology, Biruni University, Istanbul, Turkey

2 Department of Otorhinolaryngology, Istanbul Sancaktepe, Education and Research Hospital, Istanbul, Turkey

3 Department of Radiology, Acrbadem Kozyatagi Hospital, Istanbul, Turkey

4 Department of Neurology, Istanbul Medipol University, Istanbul, Turkey course of this pandemic, in addition to the initially described symptoms like fever, cough, and shortness of breath, other symptoms that were not initially recognized like olfactory and gustatory dysfunctions have been started to be reported $[2,3]$. Increased recognition of these olfactory/gustatory

5 Department of General Surgery, Cerrahpasa Medical Faculty, Istanbul University-Cerrahpasa, Istanbul, Turkey

6 Department of Internal Medicine, Istanbul Medipol University, Istanbul, Turkey

7 Department of Otorhinolaryngology, Medicalpark Florya Hospital, Istanbul, Turkey

8 Department of Radiology, The University of Iowa, Iowa, USA

9 Department of Otorhinolaryngology, Istanbul University-Cerrahpaşa, Istanbul, Turkey 
symptoms is extremely important not just for patient management, but also for timely initiation of isolation precautions to curb the spread of this pandemic. Additionally, earlier detection of the disease may increase the overall prognosis of the patient by earlier utilization of diagnostic procedures and timely initiation of treatment [4].

There is increased recognition of loss of smell and taste complaints in patients with confirmed COVID-19 infection [5-7]. However, pathogenesis of anosmia related to SARSCoV-2 has not been clearly defined [5]. Olfactory dysfunction may be isolated and with sudden onset followed by usual progression to anosmia over time. While incidence of loss of smell has been reported in up to $>80 \%$ of COVID-19 patients in some series, $11.8-35.5 \%$ of patients may exhibit olfactory dysfunction without any other symptoms [6, 7]. Majority of patients do not have nasal obstruction or rhinorrhea symptoms, and olfactory dysfunction usually occurs without sinonasal disease, which renders COVID-19 related olfactory dysfunction distinct from the rest of post-viral olfactory dysfunction $[5,6]$.

Details of olfactory dysfunction in COVID-19 patients are still vague and more research to define its relation to other clinical findings, course over time, and potential pathogenesis would help to better characterize and understand the disease.

This study aimed to determine the clinical features of olfactory dysfunction observed in patients with COVID19 and describe its temporal evolution through the disease course and relation to other clinical symptoms.

\section{Materials and methods}

\section{Participants}

In this study, we aimed to evaluate the temporal evolution of odor disorder in a cohort of COVID-19 patients admitted to our hospital. We retrospectively reviewed the hospital database for COVID-19 patients presenting to a single institution. COVID-19 infection was confirmed either by polymerase chain reaction (PCR) on a swab test and/or findings of pneumonia consistent with COVID-19 pneumonia on chest computed tomography (CT). We identified a total of 217 patients discharged prior to end of March 2020. Detailed medical histories of the patients were obtained from hospital records. Patients with previous head trauma, chronic sinonasal disease, neurological disease, metabolic disease, pregnancy, and age $<18$ years were excluded.

The patients were then contacted via phone calls and a survey using structured questionnaires focusing on general clinical findings and sense of smell was performed. Information on the presence of olfactory dysfunction, its onset, overall course and accompanying findings was obtained.
Patients' complaints related to COVID-19 were listed in a chronological order. This study was approved by the Institutional Ethical Committee (KAEK No: 315) and was performed in accordance with the Declaration of Helsinki.

Based on olfactory dysfunction status, general symptoms, ENT symptoms, and the clinical course of these symptoms, the patients were divided into four groups: Group 1 included patients with isolated, sudden-onset loss of smell and no other complaints during disease course or follow-up, but hospitalized for chest CT findings; group 2 included patients with initial sudden-onset loss of smell, followed by COVID19 related symptoms like fever, cough, shortness of breath, sore throat, and diarrhea; group 3 included patients with initial COVID-19 related complaints and gradual development of olfactory dysfunction; and group 4 included patients with COVID-19 related complaints without any olfactory dysfunction during the disease.

\section{Evaluation of olfactory function}

Olfactory functions were evaluated using the questionnaire by phone for the assessment of self-reported olfactory function and olfaction-related quality of life, which tests the subjective olfactory capability (SOC) [8]. Due to COVID-19 measures, these patients were not further evaluated with objective olfaction tests such as Sniffin' Sticks test to minimize disease spread and contamination risk. SOC of the patients before the disease, during the disease, and during the recovery period was assessed. In order to assess the olfactory discrimation, patients were asked to rate odor identification from common household supplies including spice (tangerine, mint, clove, ginger), drink (Turkish coffee or Turkish raki), a cleaning supply (Clorox or soap) and lemon cologne (widely available across households due to traditional usage, and frequently used as a disinfectant during the pandemic). Self-scoring was used to assess the olfactory function. All the patients were asked to rate their ability to smell on a scale of $1-10(0$, unable to smell; 10 , best possible sense of smell) [8]. This form was specifically integrated with questions regarding the olfactory function during the disease in order to assess the subclinical course of olfactory dysfunction in patients with COVID-19.

Differences in the self-rating scores prior to and during the disease among groups 1,2 , and 3 were used as an indicator of the severity of olfactory dysfunction. When calculating the olfactory dysfunction recovery rate, the difference between the odor score at the end of the first month and the odor score prior to disease was expressed as percentile.

\section{Statistical analysis}

Statistical analyses were performed using SPSS for Windows, version 21 (SPSS, Chicago, IL, USA). Shapiro-Wilk 
test was used to check the normal distribution of the variables. Continuous variables were presented as mean \pm standard deviation (SD), and categorical variables as frequency ( $n$ ) and percentage (\%). Kruskal-Wallis test, Mann-Whitney $U$ test, and Wilcoxon signed-rank test were used to compare the scores prior to disease, during the disease and recovery period. A two-sided $p$ value $\leq 0.05$ was considered statistically significant.

\section{Results}

Out of a total of 217 patients presented with COVID-19 during March 2020, 38 patients could not be reached subsequently, two patients succumbed to the disease, three patients had chronic olfactory issues, 10 patients did not accept the survey, and 29 patients could not provide clear information about the symptoms. Thus, a total of 135 patients (61 females and 74 males) aged $39.8 \pm 11.3$ (18-66) years were interviewed. Average duration between the onset of olfactory dysfunction and survey was 31.9 $\pm 2.8(21-40)$ days.

Group 1 comprised 14 patients $(10.4 \%)$, group 2 of 42 patients $(31.1 \%)$, group 3 of 24 patients (17.8\%), and group 4 of 55 patients $(40.7 \%)$. In total, $59.3 \%$ of the patients had olfactory complaints. Further information on demographic data and clinical characteristics of the groups are provided in Table 1.

Cases with olfactory dysfunction (groupss I-III) were significantly younger with female predominance (mean age $37.1 \pm 10.6(22-65)$ years; $58.8 \%$ females) compared to patients without olfactory dysfunction (group 4; mean age $43.7 \pm 11.3(18-66)$ years; $25.5 \%$ females $)(p=0.001$ and $p<0.001$, respectively). There was no significant difference in age distribution among the subgroups with olfactory dysfunction.

Self-rating olfactory scores prior to disease were higher in group $1(9.4 \pm 0.5(9-10))$ than in group $2[8.8 \pm 1$ $(6-10)]$ and $3[8.8 \pm 1.3(6-10)](p=0.005$ and $\mathrm{p}=0.03$, respectively) (Fig. 1), (Table 2 ). The olfactory dysfunction

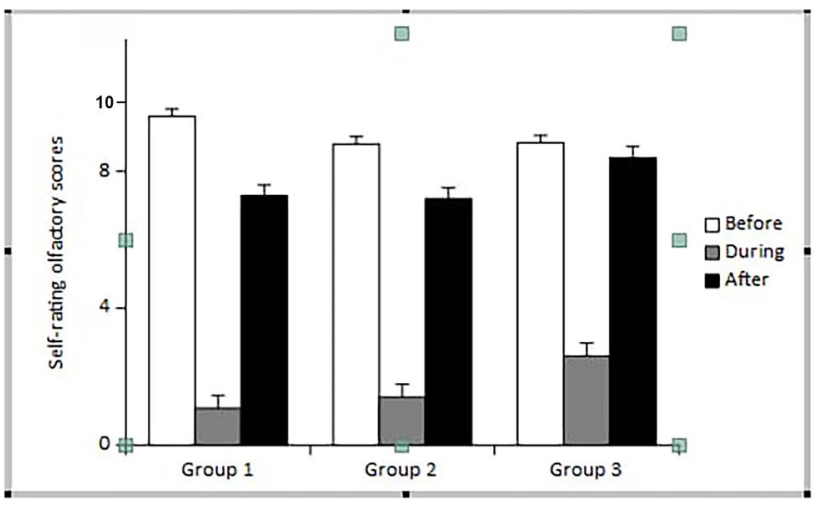

Fig. 1 Self-rating olfactory scores

severity during COVID-19 infection was significantly higher in group $1(8.4 \pm 1.9(3-10))$, compared to group 2 [7.6 2 $(3-10)]$ and 3 [6.2 $2.6(1-10)]$, (Fig. 1), (Table 2). Similarly, olfactory dysfunction severity in group 2 was significantly higher than group 3 (Table 2) Total loss of smell (selfrating score: 0 ) was reported in a total of $64.3 \%, 59.5 \%$, and $29.2 \%$ of patients in groups 1, 2, and 3, respectively (Fig. 2).

In these three groups, the odor scores after recovery from COVID-19 infection were significantly lower compared to scores prior to disease onset. The residual olfactory dysfunction was similar between groups 1 and 2, but was more evident than group 3 ( $p=0.01)$.

Olfactory scores completely returned back to the predisease scores in $51.2 \%$ of patients (41 patients) with olfactory dysfunction, with a mean duration of olfactory dysfunction of $7.8 \pm 3.1(2-15)$ days. Sense of smell recovered by $75-100 \%$ in $75 \%$ of patients with a mean duration of olfactory dysfunction in $8.4 \pm 3.4$ days. Rate of complete olfactory dysfunction recovery was higher in group 3 compared to groups 1 and 2 (28.6\% in group 1, 50\% in group 2 , and $66.7 \%$ in group $3 ; p=0.023$ and $p=0.189$, respectively) (Fig. 2). Similarly, recovery of olfactory dysfunction by $75-100 \%$ was more prevalent in group 3 compared to groups 1 and 2 (57.1\% in group $1,66.7 \%$ in group 2, and
Table 1 Demographics and clinical characteristics of the groups

\begin{tabular}{|c|c|c|c|c|}
\hline Groups & Age (years) & Gender (F/M) $n(\%)$ & Comorbidities (\%) & Smoking \\
\hline Group $1 n=14$ & $35.4 \pm 9.5(25-54)$ & $12(85.7 \%) / 2(14.3 \%)$ & Bronchitis $14.3 \%$ & $2(14.3 \%)$ \\
\hline Group $2 n=42$ & $37.6 \pm 11(22-65)$ & $26(61.9 \%) / 16(38.1 \%)$ & $\begin{array}{c}\text { Hypertension } 7.1 \% \\
\text { Bronchitis } 7.1 \% \\
\text { Cardiac disease } 2.4 \%\end{array}$ & $4(9.5 \%)$ \\
\hline Group $3 n=24$ & $37.2 \pm 10.6(23-61)$ & $9(37.5 \%) / 15(62.5 \%)$ & $\begin{array}{l}\text { Hypertension } 4.2 \% \\
\text { Bronchitis } 4.2 \%\end{array}$ & $9(37.5 \%)$ \\
\hline Group $4 n=55$ & $43.7 \pm 11.3(18-66)$ & $14(25.5 \%) / 41(74.5 \%)$ & $\begin{array}{l}\text { Cardiac disease 5.5\% } \\
\text { Hypertension 5.5\% } \\
\text { Diabetes 3.6\% } \\
\text { Bronchitis 3.6\% }\end{array}$ & $11(20 \%)$ \\
\hline
\end{tabular}

Values are presented as mean \pm standard deviation (SD), $F$ Female, $M$ Male 
Table 2 Olfactory function features of groups

\begin{tabular}{llrllll}
\hline & Group 1 & Group 2 & Group 3 & $P^{1}$ & $P^{2}$ & $P^{3}$ \\
\hline $\begin{array}{l}\text { Before olfactory } \\
\text { scores (self- }\end{array}$ & $9.4 \pm 0.5(9-10)$ & $8.8 \pm 1(6-10)$ & $8.8 \pm 1.3(6-10)$ & $\mathbf{0 . 0 0 5}^{*}$ & $\mathbf{0 . 0 3}^{*}$ & 0.911 \\
rating) & & & & & & \\
OD severity & $8.4 \pm 1.9(3-10)$ & $7.6 \pm 2(3-10)$ & $6.2 \pm 2.6(1-10)$ & $\mathbf{0 . 0 4 0}^{*}$ & $\mathbf{0 . 0 0 3}^{*}$ & $\mathbf{0 . 0 4 8}^{*}$ \\
Duration (days) & $8.3 \pm 2.9(5-14)$ & $(8.5 \pm 3.6(2-15)$ & $6.3 \pm 1.5(4-10)$ & 0.909 & $\mathbf{0 . 0 3 6}^{*}$ & $\mathbf{0 . 0 3 2}^{*}$ \\
\hline
\end{tabular}

Values are presented as mean \pm standard deviation (SD); $O D$ Olfactory dysfunction; $P^{1}$ Group 1 vs. Group 2; $P^{2}$ Group 1 vs. Group 3; $P^{3}$ Group 2 vs. Group 3

*Mann-Whitney U test

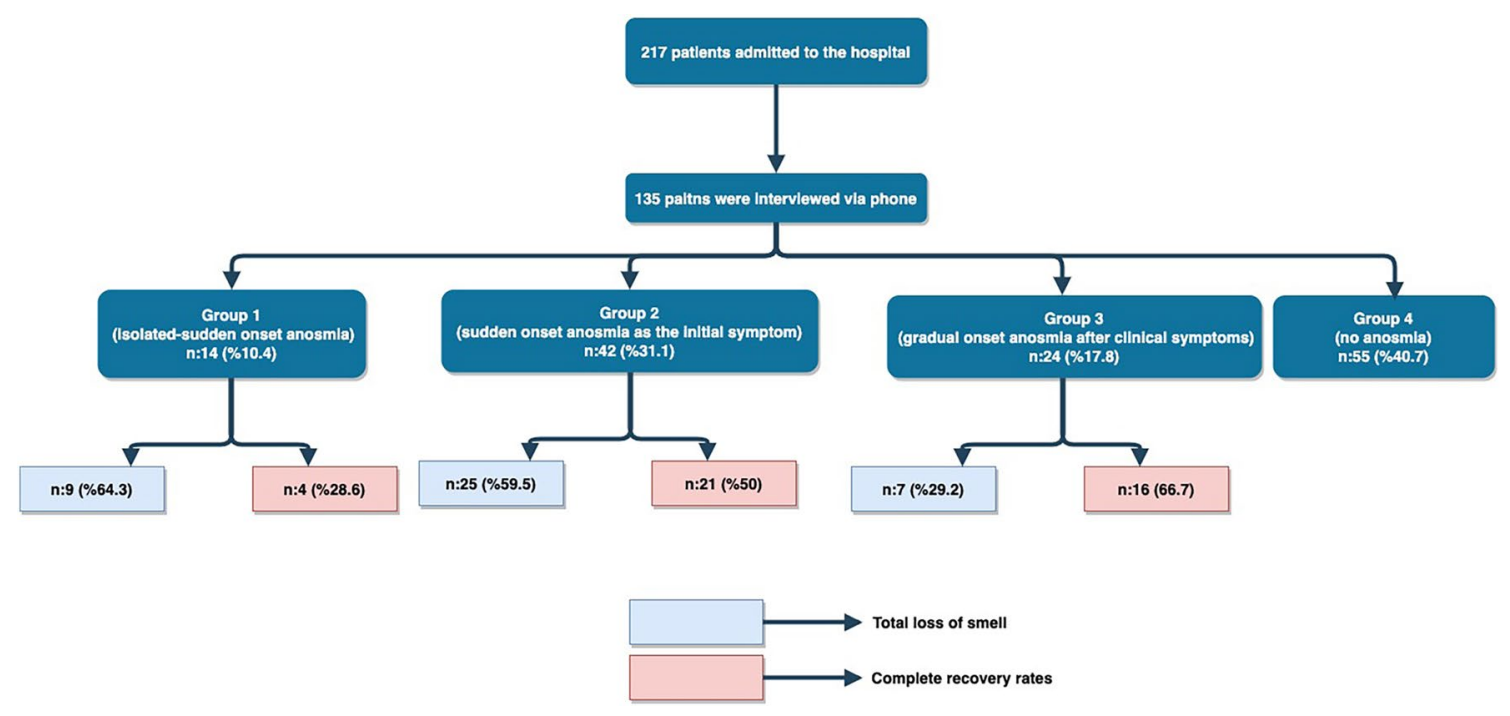

Fig. 2 The flowchart summarizing percentages of total loss of smell and complete recovery rates by groups

$100 \%$ in group $3, \mathrm{p}=0.01$ and $p<0.001$, respectively). Duration of loss of smell was longer in groups $1(8.3 \pm 2.9(5-14)$ days) and $2[8.5 \pm 3.6(2-15)$ days] than in group $3(6.3 \pm 1.5$ (4-10) days] ( $p=0.036$ and $p=0.032$, respectively; Table 2).

Cases who developed other COVID-19 related symptoms after initial olfactory dysfunction, interval between olfactory dysfunction and other COVID-19 related findings was $1.6 \pm 2.6(0-15)$. Fever (59.1\%), cough (53\%), and diarrhea $(45.5 \%)$ were the most common findings in patients with olfactory dysfunction. Olfactory dysfunction and co-existing typical COVID-19 symptoms are presented further in Table 3. Nasal congestion symptoms was more prevalent in cases with olfactory dysfunction [12 cases (18.2\%)] compared to patients without olfactory dysfunction [3 cases $(5.5 \%)](p=0.034)$.

\section{Discussion}

Olfactory dysfunction has been reported at a high rate in COVID-19 patients in more recent studies, with suggestions to include sudden-onset anosmia as a screening criterion
Table 3 Olfactory dysfunction and coexisting COVID-19 related symptoms

\begin{tabular}{lccl}
\hline Symptoms & $\begin{array}{l}\text { Patients with OD } \\
(\text { Groups 2-3) } n(\%)\end{array}$ & $\begin{array}{l}\text { Patients without } \\
\text { OD (Group 4) } n\end{array}$ & $p$ \\
\hline Fever & $39(59.1 \%)$ & $30(54.5 \%)$ & 0.615 \\
Cough & $35(53 \%)$ & $21(38.2 \%)$ & 0.103 \\
Diarrhea & $30(45.5 \%)$ & $6(10.9 \%)$ & $\mathbf{0 . 0 0 0}$ \\
Muscle ache & $14(21.2 \%)$ & $7(12.7 \%)$ & 0.220 \\
Dispnea & $8(12.1 \%)$ & $4(7.3 \%)$ & 0.374 \\
Nasal congestion & $12(18.2 \%)$ & $3(5.5 \%)$ & $\mathbf{0 . 0 3 4}$ \\
Headache & $5(7.6 \%)$ & $6(10.9 \%)$ & 0.525 \\
Throat pain & $3(4.5 \%)$ & $8(14.5 \%)$ & 0.057 \\
Fatigue & $14(21.2 \%)$ & $18(32.7 \%)$ & 0.153 \\
Appetite loss & $5(7.6 \%)$ & $3(5.5 \%)$ & 0.640 \\
\hline
\end{tabular}

$O D$ Olfactory dysfunction

*Mann-Whitney U test

for COVID-19 [8, 9]. Initial experience regarding the differences in clinical presentations/disease course of these patients has been published in large-case series; however, no 
subgroup analysis to better delineate the study populations has been performed $[6,7,9]$. The distinguishing feature of the current study is segregation of COVID-19 related olfactory dysfunction into different patterns to better characterize the clinical course of COVID-19 related olfactory dysfunction. In this study, we observed three different patterns of olfactory dysfunction in COVID-19 disease as (1) isolated, sudden-onset loss of smell and no other complaints during disease course or follow-up; (2) initial sudden-onset loss of smell, followed by other COVID-19 symptoms; (3) initial COVID-19 complaints and gradual development of olfactory dysfunction.

Various hormonal and genetic factors may account for the gender differences in the clinical course of viral infections [10]. COVID-19 is more common, has more severe course, and is associated with higher mortality rates in males [11] While COVID-19-associated loss of smell is associated with a milder clinical course and more common in female $[6,12]$. In our study, COVID-19 related olfactory dysfunction was more prevalent in females, and patients with olfactory dysfunction were younger compared to those without hyposmia/ anosmia. This might be related to better sense of smell in women than men and increased sensitivity of females to any change in olfactory function as they use their sense of smell more frequently in daily life.

\section{Pathogenesis of COVID-19 anosmia}

Several theories have been proposed to explain the pathogenesis of COVID-19 related anosmia. One plausible mechanism is high viral load in nasal mucosa with secondary inflammation which may result in direct injury to olfactory epithelium [13]. Another plausible mechanism involves angiotensin converting enzyme 2 (ACE2) receptors [14]. The olfactory epithelium has been found to express ACE2 and TMPRSS2, which may enable SARS-CoV-2 to invade the olfactory mucosa and olfactory bulb, and result in subsequent dysfunction [14-16]. However, ACE2 expression is mainly seen in non-neuronal cell types like sustentacular, Bowman's gland, and microvillar cell, favoring indirect mechanisms of injury [17].

An interesting observation in this study was the more severe and longer olfactory dysfunction in patients with isolated, sudden-onset loss of smell compared to patients who gradually developed olfactory dysfunction. This suggests that initial loss of the olfaction due to immune response at nasal cavity may help alleviate the systemic effects of COVID-19. This is also supported by the observations that COVID-19 patients with olfactory dysfunction have milder disease course and better prognosis compared to COVID19 cases without anosmia. Whether this mechanism helps prevent both central neuroinvasion and viremia should be further studied.
In our study, similar to the previous literature, younger patients with COVID-19 had more frequent and severe olfactory dysfunction. However, Brann et al. reported that juvenile mice had lower expression of ACE2 and TMPRSS2 in the olfactory epithelium and subsequently had lower olfactory dysfunction [17]. This discrepancy suggests that mechanisms other than ACE2 and TMPRSS2 pathway might be involved in COVID-19 related anosmia.

Olfactory cleft width is an important parameter affecting olfaction [18]. Our research group has previously showed olfactory cleft width as a risk factor for COVID-19 related anosmia $[19,20]$. As olfactory cleft width and volume increases, there is increase in mucosal surface area which may lead to higher viral load and resultant neuronal and sustentacular cell damage. Anosmia might be related to inflammation localized to olfactory cleft and seen in patients with nasal reaction due to viral load.

\section{Clinical features of COVID-19 anosmia}

A distinctive feature of COVID-19-associated anosmia is its transient course, with its sudden onset independent of other features, with gradual improvement over a short course (about 2 weeks) [6].

Nasal obstruction-related loss of smell is very common in viral infections; however, anosmia associated with COVID19 is not commonly accompanied by nasal obstruction/congestion [6, 14, 21]. Similarly, in our study, the association of olfactory dysfunction with nasal congestion was found to be low with a ratio of $18.2 \%$. Kaye et al. reported that in cases with COVID-19 anosmia 25\% had nasal congestion and 18\% had rhinorrhea [22]. This supports the hypothesis that mechanisms other than obstruction are involved in COVID-19 anosmia. Olfactory scores completely returned back to the pre-disease scores in $51.2 \%$ of patients after a mean duration of $7.8 \pm 3.1(2-15)$ days. The rates of complete and partial recovery of olfactory dysfunction in Kaye et al.'s study were $13 \%$ and $14 \%$, respectively [22]. Our study had significantly higher olfactory function recovery rate. Available literature supports spontaneous improvement with a mean duration of 2-3 weeks [23, 24]. However, cases with symptoms lasting more than 1 month, so called persistent anosmia, have also been reported [25-27]. Considering the fact that olfactory epithelium undergoes regeneration over 6-8 weeks, SARS-COV2 may result in anosmia longer than 2-3 weeks due to the epithelia damage caused [28]. Kandemirli et al. and Klein et al. reported cases with persistent anosmia at 4-month and 6-month period, respectively, suggesting that there might be other potential mechanisms beyond epithelial damage that lead to permanent anosmia. Further data on this permanent anosmia are important to highlight the pathogenesis of COVID-19 anosmia. 
The difference of our study from similar studies in the literature is as follows: we evaluated the severity and duration of anosmia, and total recovery rates in isolated anosmia cases compared to the patients who have anosmia accompanying other clinical symptoms. We found that that patients with isolated, sudden-onset loss of smell had more severe olfactory dysfunction, which seemed to correlate with the longer recovery times in these patients.

\section{Temporal relationship to other clinical symptoms}

The most common presenting symptoms of COVID-19 including fever, cough, and headache can be seen in other nonspecific viral upper respiratory tract infections $[2,29$, 30]. In our study, fever (59.1\%), cough (53\%), and diarrhea (45.5\%) were the most common symptoms encountered in patients with olfactory dysfunction. Olfactory dysfunction may start before, after, or simultaneously with these clinical symptoms, or it may be the only symptom. Kaye et al. reported that olfactory dysfunction preceded COVID-19 diagnosis in $73 \%$ of cases and $27 \%$ of cases had anosmia as an isolated symptom [22]. In our study, with lower rates, olfactory dysfunction preceded COVID-19 diagnosis in $41.5 \%$ of cases, and in $10.4 \%$ of cases, anosmia was the sole symptom.

Different studies across the world assessed the olfactory function based on questionnaires to limit contamination and spread. For the same reason, we used a similar questionnaire-based approach instead of objective psychophysical olfactory test. This constitutes the main limitation of our study [5-7, 31]. Additionally, survey was performed after hospital discharge with a relatively long-interval questioned during the disease course introducing an element of recall bias. Another limiting factor is the single-center nature of the study with relatively limited number of total cases.

\section{Conclusion}

The fact that more than 50\% patients with COVID-19 develop sudden-onset anosmia prior to respiratory symptoms makes it an important ancillary sign for the disease. Detailed evaluation of the characteristics of olfactory dysfunction and early identification and isolation of symptomatic and asymptomatic carriers are important both for patient management and contact isolation.

Our study described the different temporal evolution of COVID-19-related anosmia with other clinical symptoms to further characterize this symptom. In isolated anosmia cases, anosmia was more severe and complete recovery rates were lower compared to the patients who have other clinical symptoms. Further studies on the pathogenesis of COVID19-related olfactory dysfunction will contribute not only to the pathogenesis of post-viral olfactory loss (PVOL), but also to the immune response in COVID-19 infection.

Acknowledgements This study was designed in line with the opinions and suggestions of Professor Thomas Hummel, one of the world's bestknown scientists and clinicians on anosmia. We owe him thanks.

Funding The authors received no financial support for the research, authorship, and/or publication of this article.

\section{Compliance with ethical standards}

Conflict of interest The authors declare that there is no conflict of interest regarding the publication of this article.

Ethical approval Ethical approval for this study was obtained from the local ethics committee (2020-05/28).

Informed consent Informed consent was obtained from all individual participants included in the study.

\section{References}

1. World Health Organization (2020) Coronavirus disease 2019 (COVID-19): situation report. . https://www.who.int/docs/defau 1t-source/coronaviruse/situation-reports/20200816-covid-19-sitre p-209.pdf?sfvrsn=5dde1ca2_2 (Accessed Aug 30, 2020)

2. Chen N, Zhou M, Dong X et al (2020) Epidemiological and clinical characteristics of 99 cases of 2019 novel coronavirus pneumonia in Wuhan, China: a descriptive study. Lancet 395:507-513. https://doi.org/10.1016/S0140-6736(20)30211-7

3. Giacomelli A, Pezzati L, Conti F et al (2020) Self-reported Olfactory and taste disorders in patients with severe acute respiratory coronavirus 2 infection: a cross-sectional study. Clin Infect Dis 71:889-890. https://doi.org/10.1093/cid/ciaa330

4. Wang D, Hu B, Hu C et al (2020) Clinical characteristics of 138 hospitalized patients with 2019 novel Coronavirus-1nfected pneumonia in Wuhan China. JAMA 323:1061-1069. https://doi. org/10.1001/jama.2020.1585

5. Gane SB, Kelly C, Hopkins C (2020) Isolated sudden onset anosmia in COVID-19 infection. A novel syndrome? Rhinology 58:299-301. https://doi.org/10.4193/Rhin20.114

6. Lechien JR, Chiesa-Estomba CM, De Siati DR et al (2020) Olfactory and gustatory dysfunctions as a clinical presentation of mild-to-moderate forms of the coronavirus disease (COVID19): a multicenter European study. Eur Arch Otorhinolaryngol 277:2251-2261. https://doi.org/10.1007/s00405-020-05965-1

7. Beltrán-Corbellini Á, Chico-García JL, Martínez-Poles J et al (2020) Acute-onset smell and taste disorders in the context of COVID-19: a pilot multicentre polymerase chain reaction based case-control study. Eur J Neurol. https://doi.org/10.1111/ ene.14273 ((Published online ahead of print, 2020 Apr 22))

8. Wee LE, Chan YFZ, Teo NWY et al (2020) The role of selfreported olfactory and gustatory dysfunction as a screening criterion for suspected COVID-19. Eur Arch Otorhinolaryngol 277:2389-2390. https://doi.org/10.1007/s00405-020-05999-5

9. Yan CH, Faraji F, Prajapati DP, Boone CE, DeConde AS (2020) Association of chemosensory dysfunction and COVID-19 in patients presenting with influenza-like symptoms. Int Forum Allergy Rhinol 10:806-813. https://doi.org/10.1002/alr.22579 
10. Klein SL (2012) Sex influences immune responses to viruses, and efficacy of prophylaxis and treatments for viral diseases. BioEssays 34:1050-1059. https://doi.org/10.1002/bies.201200099

11. Mo P, Xing Y, Xiao Y et al (2020) Clinical characteristics of refractory COVID-19 pneumonia in Wuhan, China. Clin Infect Dis. https://doi.org/10.1093/cid/ciaa270 ((Published online ahead of print, 2020 Mar 16))

12. Klopfenstein T, Kadiane-Oussou NJ, Toko L et al (2020) Features of anosmia in COVID-19. Med Mal Infect 50:436-439. https:// doi.org/10.1016/j.medmal.2020.04.006

13. Zou L, Ruan F, Huang M et al (2020) SARS-CoV-2 viral load in upper respiratory specimens of infected patients. N Engl J Med 382:1177-1179. https://doi.org/10.1056/NEJMc2001737

14. Tekcan Sanli DE, Altundag A, Kandemirli S et al (2020) Relationship between disease severity and serum IL-6 levels in COVID-19 anosmia. Am J Otolaryngol 42:102796. https://doi.org/10.1016/j. amjoto.2020.102796 ((Published online ahead of print, 2020 Oct 28))

15. Youngentob SL, Schwob JE, Saha S, Manglapus G, Jubelt B (2001) Functional consequences following infection of the olfactory system by intranasal infusion of the olfactory bulb line variant (OBLV) of mouse hepatitis strain JHM. Chem Senses 26:953963. https://doi.org/10.1093/chemse/26.8.953

16. Gengler I, Wang JC, Speth MM, Sedaghat AR (2020) Sinonasal pathophysiology of SARS-CoV-2 and COVID-19: a systematic review of the current evidence. Laryngoscope Investig Otolaryngol 5:354-359. https://doi.org/10.1002/lio2.384

17. Brann D, Tsukahara T, Weinreb C, Logan DW, Datta SR (2020) Non-neuronal expression of SARS-CoV-2 entry genes in the olfactory system suggests mechanisms underlying COVID-19-associated anosmia. Sci Adv 6:eabc5801. https://doi.org/10.1126/ sciadv.abc5801

18. Loftus C, Schlosser RJ, Smith TL et al (2020) Olfactory cleft and sinus opacification differentially impact olfaction in chronic rhinosinusitis. Laryngoscope 130:2311-2318. https://doi. org/10.1002/lary.28332

19. Altundag A, Yildırım D, Tekcan Sanli DE et al (2020) Olfactory Cleft measurements and COVID-19-related anosmia. Otolaryngol Head Neck Surg 1:194599820965920. https://doi. org/10.1177/0194599820965920 ((published online ahead of print, 2020 Oct 13))

20. Yildirim D, Altundag A, Tekcan Sanli DE et al (2020) A new perspective on imaging of olfactory dysfunction: does size matter? Eur J Radiol 132:109290. https://doi.org/10.1016/j.ejrad .2020 .109290 ((Published online ahead of print, 2020 Sep 18))

21. Huart C, Philpott C, Konstantinidis I et al (2020) Comparison of COVID-19 and common cold chemosensory dysfunction.
Rhinology. https://doi.org/10.4193/Rhin20.251 ((Published online ahead of print, 2020 Aug 19))

22. Kaye R, Chang CWD, Kazahaya K, Brereton J, Denneny JC (2020) COVID-19 anosmia reporting tool: initial findings. Otolaryngol Head Neck Surg 163:132-134. https://doi.org/10.1177/01945 99820922992

23. Hornuss D, Lange B, Schröter N, Rieg S, Kern WV, Wagner D (2020) Anosmia in COVID-19 patients. Clin Microbiol Infect 26:1426-1427. https://doi.org/10.1016/j.cmi.2020.05.017

24. Heidari F, Karimi E, Firouzifar M et al (2020) Anosmia as a prominent symptom of COVID-19 infection. Rhinology 58:302-303. https://doi.org/10.4193/Rhin20.140

25. Kandemirli SG, Altundag A, Yildirim D, Tekcan Sanli DE, Saatci O (2020) Olfactory Bulb MRI and paranasal sinus CT findings in persistent COVID-19 anosmia. Acad Radiol 1:1076-6332. https ://doi.org/10.1016/j.acra.2020.10.006 ((Published online ahead of print, 2020 Oct 19))

26. Tsivgoulis G, Fragkou PC, Lachanis S et al (2020) Olfactory bulb and mucosa abnormalities in persistent COVID-19 induced anosmia: a magnetic resonance imaging study. Eur J Neurol. https:// doi.org/10.1111/ene.14537 ((Published online ahead of print, 2020 Sep 16))

27. Klein H, Asseo KN et al (2020) Onset, duration, and persistence of taste and smell changes and other COVID-19 symptoms: longitudinal study in Israeli patients. medrXiv. https://doi. org/10.1101/2020.09.25.20201343 ((Published online ahead of print, 2020 Oct 17))

28. Bonenberger A (2020) Anosmia: COVID-19's mysterious side effect. Yale Medicine. https://medicine.yale.edu/news/yalemedicine-magazine/anosmia-covid19s-mysterious-side-effect/. (Accessed 05 Nov 2020).

29. Li LQ, Huang T, Wang YQ et al (2020) COVID-19 patients' clinical characteristics, discharge rate, and fatality rate of meta-analysis. J Med Virol 92:577-583. https://doi.org/10.1002/jmv.25757

30. Guan WJ, Ni ZY, Hu Y et al (2020) Clinical characteristics of Coronavirus disease 2019 in China. N Engl J Med 382:1708-1720. https://doi.org/10.1056/NEJMoa2002032

31. Parma V, Ohla K, Veldhuizen MG et al (2020) More than smellCOVID-19 is associated with severe impairment of smell, taste, and chemesthesis. Chem Senses 45:609-622. https://doi. org/10.1093/chemse/bjaa041

Publisher's Note Springer Nature remains neutral with regard to jurisdictional claims in published maps and institutional affiliations. 